Mapping the Complexities and Highlighting the Dangers: The Global Drive to End FGM in the UK and Sudan

\author{
Nafisa Bedri and Tamsin Bradley
}

Dr. Nafisa M. Bedri

Associate Professor in Women and Reproductive Health,

Director, International \& External Relations Office

Ahfad University for Women

Omdurman, P.O.Box 167, Sudan

Tel: Work: $+249187553363 \quad+249187553363 / 15494504$

Mobile: $+\underline{249912915694 \quad+249912915694}$

Fax: +249 187579111

www.ahfad.edu.sd/ www.ahfad.org

Dr Tamsin Bradley (Corresponding Author)

Reader in International Development Studies

University of Portsmouth

Park Building

King Henry Street

Portsmouth

PO1 2DZ

02392846143 


\title{
Mapping the Complexities and Highlighting the Dangers: The Global Drive to End FGM in the UK and Sudan
}

\begin{abstract}
This article maps out the UK Department for International Development's (DFID) global push to end the practice of Female Genital Mutilation/Cutting (FGM/C). In particular it looks at how the various components aim to link together filling evidence gaps and seeking to identify what works to finally end this brutal practice. Throughout the article we voice a caution that if the numerous programmes emerging are not shaped by grassroots experiences of FGM, and specifically by local change agents, there is real danger that this opportunity will fail. In highlighting this danger we present the viewpoint of community groups and local activists in the UK and also Sudan. We place these voices within the complex web of interventions that comprise the Free Sudan from FGM/C programme. If not sufficiently coordinated and responsive to communities it simply will not work. To emphasise this caution we draw on a variety of theories that help us understand how discourses around FGM have emerged and intertwine. We also draw on theory to highlight an over reliance on a constructed image of a suffering FGM victim which makes it difficult for local activists to be heard.
\end{abstract}

\section{Introduction}

On February 6 $6^{\text {th }} 2014$ the UK government launched 'International Zero Tolerance of FGM' day. The UK Department for International Development then pledged 36 Million to end FGM and Childmarriage over the next five years making it the largest donor globally. The money has been allocated to support three programmes of work. Firstly, DFID is funding ‘The Girls Generation’ which represents a Social Movement specifically focusing on ending FGM. Secondly, a consortium led by the Population Council in Nairobi have been commissioned to generate new research to aid our understanding of FGM in terms of its prevalence, why it happens and the most effective approaches to ending it. Thirdly money has been allocated to support the 'Free Sudan from FGM/C' intervention programme. Sudan has been identified as the model case for intervention and in addition to receiving money through the DFID programme is also the focus of a country based social movement called Saleema funded by the UNJP (which DFID also supports). The DFID Free Sudan programme is being led by three UN agencies, UNICEF, UNFPA and WHO. This article will do two things; firstly it will map out the intersections of this global push to end FGM highlighting the emerging complexities in programming and policy making as different initiatives converge. We focus on how multiple strands of funding have produced a highly complex web of policies and interventions in Sudan. Through this mapping exercise we will urge a cautionary note. Such policy and programme complexity, most of which is designed by global and national agencies and governments, carries the danger of ignoring even side stepping important change agents who are already challenging FGM from within. Harnessing social and political capital at all levels, including the local, will be essential. In making this argument we present a number of activist voices within 'cutting communities' in the UK and 
Sudan. The energy and commitment apparent in their viewpoints adds weight to our argument that the capital and resource to shift mind-sets exists and must be utilised. This article carries the intention of raising this concern at a crucial juncture in the end FGM campaign. This is an important moment in history for women within cutting communities and all efforts must be joined up but also informed by the lived experiences of men and women affected.

In order to convey our concerns convincing we frame them theoretically drawing from anthropology on the notion of a deconstructed suffering and pitiful 'other'. The global FGM campaign has certainly generated such an object and the moral dangers associated with this process of binary othering for successful intervention will be considered. This article will consider then the challenges facing those who report, campaign and research on this issue, in particular the ethical complexities of representing victims of FGM. How can FGM campaigns be framed in such a way so as to promote the agency of women from so-called cutting communities rather than deny it? The overall argument states that, we must think in a far more deep rooted and critical way about how to end FGM both in terms of understanding how social change happens but also in thinking through more carefully how to engage women and men on different sides of the FGM continuum (supporters through to activists) in a way that does not reduce the debate to a binary between 'victim' and 'liberated', between those that 'know' FGM is wrong and those who 'believe' it is an intrinsic part of their cultural identity. The article concludes by reviewing the questions that remain unanswered in relation to FGM. What do we need to know if we are to end it?

Both of us are involved in the global FGM campaign working together in Sudan generating new knowledge to understand better the triggers for mind-set change which, it is hoped, will support the success of the intervention programme. We have applied qualitative social science approaches in this article through in-depth open ended interviews with women from cutting communities in the UK and Sudan. We have then sought to use these interviews to piece together the cautionary argument that forms the heart of this article.

The article is structured as follows; the first section presents a descriptive overview of the global campaign highlighting the complexity present in the converging strands. Section two shifts to our theoretical frame and situates our argument clearly within anthropological concepts of suffering and pity. Section three focuses on the local activists who argue their work and viewpoints are being squeezed by the over focus on top-down change. Section fours then returns to Sudan as the global focal point for efforts to end FGM and applies our cautionary notes to the evolving movement there. The conclusion will acknowledge the commitment and efforts of all who are evolved in the global push to end this practice but state the importance of stopping points along the way for critical reflection around the question of inclusion, specifically that of local change-agents.

\section{Mapping the Programme Globally}

As stated in the introduction the DFID's global programme consists of three components whilst intersecting with various additional UN initiatives. 'The Girls Generation' is a global movement working across African countries including Sudan, Kenya, Senegal and the Gambia, that practice FGM and transnationally with the corresponding diaspora communities in the UK. Its intention is to utilise marketing and advertising mechanisms to produce a branded communication-activist-advocacy strategy directed at cutting communities in order to change mind-sets supportive of the practice. 
The second component is the research programme lead by the Population Council in Nairobi and will generate important new data in a number of African countries including Kenya, Sudan and Senegal. Key research themes include understanding shifts in the types of FGM practiced, the impact of medicalisation of FGM, and the identification of specific triggers for mind-set change (cultural, political, economic). The underlying objective of the research is to gather evidence to support programme design. In other words to work out 'what works' to change social norms around FGM. Both the research programme and the girl generation is working in Sudan. However Sudan itself is also the focus for DFID's last component the 'pilot model intervention'. Significant funding (multiple millions) is being poured into Sudan via three UN agencies (WHO, UNICEF and UNFPA), and the government of Sudan's National Commission for Child and Women's Welfare (NCCW). The structure of this component will be outlined in detail in section four.

Underlying and shaping these components are a number of discourses of FGM. In analysing these discourse we draw on the work of Bacchi (2000) who urges those that link policy and discourse together to explain how specific problems emerge to think in a less liner manner. Instead she suggests; "that policy-as-discourse analysts need to spend more time theorizing the 'space for challenge'. An overemphasis on the constraints imposed by discourse/s and a tendency to concentrate upon some groups, those described as 'having' power, as the makers and users of discourse.” (2000: 12) With that in mind we proceed to summarise the way in which FGM is referred to across policy worlds and argue that the related discourses when taken into different cutting contexts are often challenged and reframed thereby critiquing suggestions that power is cascaded through a global hierarchy. Ultimately change will only occur when it is sparked from within the contexts under scrutiny. If we begin by reviewing national (UK) and global public policy documents, for example those produced by DFID (2014) and UNICEF (2014) the term used is FGM/C. The terminology, by including the word 'cutting', suggests they want to be careful not to offend those in favour of the practice whilst still holding a clear position. 'Cutting' as a term is descriptive and is not in and of itself emotive or politicised (see also UN Cross Agency Statement 2008). Increasingly from the late 1990's FGM/C became the term used in national government and global agency policy documents (for example, UNICEF 2013) reflecting concerns to appear 'culturally sensitive' whilst still holding that the practice is abuse. However it is interesting to observe when the terms FGM and FGM/C are used in different arenas. Differences in the use of terms can be an indication of tensions between discourses which in turn reflects the various mind-sets competing to influence the global programme. For example, at the recent Girl Summit in London (July 2014) the literature advertising the event clearly used the term 'FGM' with no inclusion of the word 'cutting'. This contradicts the advice/decision made by DFID and UNICEF who both had a role in organising the summit, to use the term FGM/C. We argue that the decision over what terminology to use is influenced by the nature of the event and even more so the strength of the feminist lobbying voice. Campaign focused media events such as summits are designed to send a clear no nonsense message and are, in the case of the girls summit, fore-grounded by activists motived more strongly by feminism rather than politicians and civil servants responsible for writing national policy who tend to be more cautious in their use of language because of fears of excluding or offending parts of the electorate. However, the question we ask throughout this article, and return in particular in the last section, is what implications do struggles over which discourse should shape the language of FGM have on the audibility of change- agents? 
The discourses intersect in a number of ways. Policy and strategy documents combine legal/rights based and medical discourses, arguing on two fronts that it is wrong because of the physical complications and that it represents a denial of basic rights. For example the following passage from a UNICEF strategy document highlights the conflation of these discourses; 'Today $\mathrm{FGM} / \mathrm{C}$ is recognized as a human rights violation and is one of many manifestations of gender inequality. In addition to excruciating pain, cutting can cause girls to bleed profusely. It may also lead to infections ... '(UNICEF 2014:3) Activists are something of a departure in that they are more likely to use terminology that best supports their political goals rather than please funders. For example organisations such as FORWARD (part of the The Girl Generation DFID consortium working in Africa and the UK) tend to be much more likely to use the term FGM and not add the word cutting (see http://www.forwarduk.org.uk/key-issues/fgm/). The terminology they use is influenced more obviously by feminist politics than can be seen in the framing of the practice in UN and national government documents. The terminology aside, the arguments used by activists (e.g. FORWARD, AFUCA, 28TooMany, Equality Now, Daughters of Eve) as to why FGM must end, as with UN agencies, stress the rights-based and medical discourses. For example FORWARD write that their vision is to see 'a world where women and girls live in dignity, are healthy, have choices and equal opportunities.' (www.FOWARD.org). Many activist organisations for example, 'Daughters of Eve' heavily stress that the practice is illegal in the UK drawing on medical evidence to stress the urgency to eradicate it. The medical discourse which emerged first in the post UN decade for women 1975-84 has and is used by campaigners to push for the eradication of FGM (Simpson 2012). In the UK such determined lobbying and graphic use of medical images and cases has successfully led to the criminalisation of the practice. The medical discourse which first shaped a global understanding of the practice through the identification of four categories of mutilation (World Health Organisation) overwhelmingly influences the work of international organisations. From the 1990's though a shift begin and FGM was reframed as an issue of rights with the UN Declaration of Human Rights used as an instrument to campaign for its eradication (Shell-Duncan 2008) and so we see the two discourses combine with arguably the language of rights more strongly used to construct a clear and hopefully pervasive message that FGM is child abuse. This intersection of medical and rights can also be seen in Sudan and will be outlined in more detail in section four. The public health sector in Sudan is highly developed not least because of the large number of medically trained professionals who seek work promoting educational messages across communities. The FGM campaign has been able to utilise this capacity and also network linking the medical implications to a rights-based concept of a whole (uncut) girl as being empowered with multiple opportunities otherwise denied (Saleema).

A cultural discourse influences those that say the practice remains important because it is a marker of tradition and identity. For example in one small qualitative study conducted in the UK such views were captured. One woman from Gambia stated; "I went through the practice when 5 years old back in Gambia, it was very traumatic, I can still recall it now. I do not blame my mother but just accept it is part of my tradition. It is very painful and problematic for women, but if I have a daughter I would put her through it because it is part of our cultural identify.” (Bodian 2015: 8) For this woman culture and tradition are the most dominant influences, whilst the emotional and physical pain and medical implications are acknowledged they are not sufficient to trigger a reversal in mind-set. For her view to change the medical and rights/legal based discourses need to strengthen diluting or even 
squeezing out the cultural dimension both in her own memory of the practice and how she views it into the future. This can certainly be seen in the context of Sudan where the cultural discourse dominates. In countries where FGM prevalence is high because it is seen as a cultural necessity the audibility and visibility of medical and rights based discourse is severely muted. The challenge faced by local activists and organisations is how to reconstruct the 'cultural' in order to remove the violent abuse that FGM represents. The helpfulness of the medical, rights and feminist discourses in triggering this process of change is unclear and largely unknown, but we argue they are unlikely individually or intesectionally to have any significant impact unless the language that shapes them comes out of the local context. In other words unless they are shaped by change-agents living within the contexts the programmes wish to transform.

Let is now apply Bacci's critique of policy-discourse analysis to the FGM discourses reviewed here. At one level we accept and support her call to understand the terrain as one in constant flux and fraught with change-tension. These tensions are influenced not just by macro actors but also by community mind-sets that throw back global discourses as insulting failing to reflect their experiences of the practice (see Malmström, and Van Raemdonck 2015). We also draw attention to the changeagents that bridge the gap between the global and the local and facilitate dialogues across and between different discourses. However, we also have to recognise that a significant amount of money is also at play which produces a power battle between the different discourse-policy approaches (see also Boyle and Sharon 2000). The political tensions that emerge utilise constructed and essentialist cultural images to further their campaign. With this in mind we move to apply anthropological theory to a critical deconstruction of how objects of pity can (unintentionally) manifest themselves unhelpfully in movement politics and consider if this has or is (even slightly) apparent in the case of the global FGM campaign. The anthropological theory we draw on helps us in framing our cautionary note that builds on, we believe, the work of scholars such as Bacci.

\section{The Social Construction of a Mutilated Victim}

Critical analysis of campaign literature and media coverage in the UK of the FGM campaign highlights the central presence of a Victim. The result of this construction is that a binary continues separating women from cutting communities from activists who stand outside presenting as liberated and largely uncut. This binary shapes a hierarchy defined not just by medical reality but also rights, between whole liberated women and cut, disempowered black women. The categories either side of this binary consume all women who look like they fit because they are African and choose not to be vocal. Outsiders are often unable to distinguish differences between those women from cultures that observe FGM and those who do not. Postcolonial critiques help us to point to the problematic terrain we are now in as we push harder than ever to End FGM (see Mohanty 1988, Nnaemeka 2000, Smith 2001). 
In order to better understand this binary how it emerges and the problems it poses for activism we turn to anthropological theory, specifically that which looks at the 'politics of suffering' and 'victimhood'. Understanding the construction of these standpoints helps to unravel the signposting within the discourses shaping End FGM programmes. Suffering and victimhood are approached within anthropology as social and cultural constructs which emerge in a number of ways through movements and also in public spaces. Kleinman states 'cultural representations of suffering images prototypical tales, metaphor models can be (and frequently are) appropriated in the popular culture or by particular social institutions for political and moral uses.' (1997: XI) If we consider the international newspaper reporting and the sudden emergence of the FGM victim within it, there are many examples but one that is representative of many clearly reveals the ways in which, yet again an African 'other' has emerged. The articles consistently carry a single photograph of a 'survivor' followed by a vivid account of their experiences of the practice and its lasting trauma. For example The Independent $9^{\text {th }}$ March 2014 carried the story of Aissa a victim who is clearly an outspoken and empowered professional woman, the brutality of her suffering projected. Whilst she is a survivor rather than a victim, applying Wade's concerns, will the readers of her story position her as such? Or will they jump through her courage and agency to her cultural heritage judging it holistically as backward? (http://www.independent.co.uk/news/uk/crime/special-report-female-genital-mutilation-unreported-ignored-and-unpunished-8439824.html) The problem is not the perceptions of FGM as abuse but the way in which it is then taken as evidence of the barbarism of the culture as a whole. As already shown in relation to FGM in Sudan prevalence is not universal and patterns of internal diversity in observance can be seen across cutting countries. Whilst the cultural discourse is dominant in terms of maintaining FGM, culture itself is diverse and fluid and should not be reduced to a single practice. Culture changes, triggering the rejection of FGM has to materialise from within in order to be lasting and widespread. The wholesale rejection of culture on the grounds that it supports practices that are violent is unlikely to produce the catalyst needed.

Anthropology has recast suffering in part as a social object rather than solely an individual or natural experience, suffering is learned, used and represented and this we see in the public medical, rights/legal and feminist discourses of FGM. These discourses are highly politicised and as Jeffery and Candea (2006) state 'victimhood establishes a space for a specific kind of politics' (2006: 289). And this space is characterised, in this instance, by moral outrage which then has a determining role in shaping the response that surfaces from the various responsible stakeholders. 'Grass-roots research on victims often involves co-construction that is moral and analytical engagement with subaltern subjects in the field of study which becomes the medium through which moral and social or political support is administered.' (Jean-Klein and Riles 2005: 176). The process of co-construction of the 'problem' is fraught with pitfalls. The likelihood of responsive and equally shared engagement emerging is dependent on the intention or rather commitment of those actors involved. Unfortunately, the politics of movements are often such that actors within them use the construction of a victim as a way of leveraging power over governments pushing them to embrace change, for example, through legislation. Whilst legislative change is important it is unlikely to be enforced without the mutual commitment and motivation of law-enforcers. The maintenance of a victim is also seen as necessary in social movements in order to mobilise the masses around the cause to build momentum which it is hoped will act as the catalyst for mind-set change. Jefferys (2006) drawing on Ferguson's ‘Anti- 
Politics Machine' argues that victimhood can negate the political with victims deliberately positioned as 'apolitical' so as to appeal to a wider pool of patrons. This we argue in the context of the global FGM movement is far from intentional but is the reality of trying every possible means to awaken populations (both those that practice FGM and those that do not) to the extreme abuse FGM represents.

Werbner (following Levinas) has pointed out perpetrators can 'violently enforce silence' (1997: 245). This of course is thought to be at the heart of FGM, as highlighted in two research reports Bodian (2015) and Afruca (2015) both looking at FGM in the UK. Both reports argue that the practice is sustained by the fear that surrounds it; young mothers retain the vivid memory of the pain and trauma, they live daily with the reminder of the violence performed on them, in a significant number of cases they do not want their daughters to go through it, yet they do not all speak out either here or in their country of 'origin'. The practice is often described as having an aura of secrecy; women do not talk about it with each other. Older women who uphold the practice are thought to be the hardest to get to speak about the practice, they maintain a stronger silence. In each case is silence really the exercising of agency or just the result of fearing repercussions, (bringing dishonour) if it is broken? Often the culture of silence is given as the reason why engaging with women from 'cutting communities' is not possible and therefore not attempted. Chapters written on FGM in Longman and Bradley (2015) seem to challenge this idea that silence is a fundamental part of FGM. As the data presented in the two reports cited above indicate women are willing to talk individually. Even now with the media hype focus group discussions are possible and not that difficult to arrange. All of which urges the question over where this idea that FGM is shrouded in secrecy comes from?

Bourdieu locates the politics of victimhood at the interface between that which can be debated (orthodoxies and heterodoxies) and the broader realm of the doxa itself; that which goes without saying because it comes without saying.' (1977: 1961) The essentialising reality is already upon us with FGM, a category of Mutilated African Woman now shapes western perceptions of all African women. This blunt categorisation blurs the internal diversity between African groups, those that practice FGM and those that do not, and the different ways the practice is observed, all of which needs to be drawn out if it is to be ended. In the UK many local councils do not carry census data on the size of the different African groups in their area. This failure to acknowledge different cultural identities is indicative of the essentialist lens through which minority communities are viewed and makes it harder for us to understand how FGM may materialise in diaspora communities.

In standing back and critically mapping the field of stakeholders involved in global and national End FGM campaigns it is clear that professional boundaries are being re-established, new terms and idioms are emerging defining a political struggle against an 'immoral other.' As Holmes writes; 'the resulting political practice is deconstructive: Its practitioners negotiate and map the points of contradictions and fatigue of particular positions. They scavenge the detritus of decaying politics, probing areas of decent and deception. By doing so they involve displaced histories and reveal deformed moralities. They strive to introduce the unvoiced and unspeakable into public discourse.' (Holmes 1993: 255) FGM is an unspeakable brutal example of what humans are capable of. Ending it is crucial for many reasons but the way forward has to be based on in-depth understanding into the complexity of how the practice manifests itself. How it is reintroduced in different contexts, for example, post migration to another country or internally as urbanisation increases. Why is it that as 
people move from village to city or into a new country where many different lifestyles and beliefs exist that they continue to perform FGM? We do not have the answers to these questions but need to find them. Reproducing essentialised images of victims will not help us get there.

\section{Problematising Representation and Positionality: Voices from the Grass-roots}

As mentioned throughout this article at the heart of End FGM campaigns and programmes is a clash between feminist discourses determined to reverse cultural perceptions of the practice as necessary and recategorise it as child abuse. Whilst we stand firmly within this discourse, it is not unproblematic for a number of reasons not least because it can lead to simplistic images of victims and perpetrators. This then in turn runs the risk of alienating members of 'cutting communities' rather than identifying, supporting and strengthening change agents from within. Feminist activists and scholars involved in the global movement (for example Hilary Burrage http://hilaryburrage.com/fgm/, Leyla Hussein http://leylahussein.com/) describe the practice as one of the most brutal forms of misogyny which exists to maintain a gender ideology rendering women inferior. It represents, so they say, the operation of power and prestige, and through concepts of shame (if a woman does not conform) and honour (because a sexually pure woman can secure a better marriage). These strongly oppositional feminist readings of why FGM happens exist alongside explanations emerging from in country research in places like Sudan that record a range views most of which suggest that FGM produces positive results. For example in Sudan communities have been documented claiming that FGM will improve fertility and prevent stillbirth. It is also believed by some that it gives husbands greater sexual pleasure thus giving women more power to sexually manipulate men to obtain material advantages. A further belief is that FGM enhances a woman's femininity by removing the parts of her body deemed to be masculine e.g. the clitoris. In the case of infibulation it is thought to achieve a smoothness considered beautiful. Religious reasons are also mentioned and sometimes used by pro FGM groups (Bedri 2013). However it should be noted that the growing body of research argues the influence of religious leadership in ending FGM is limited (see Ostebo and Ostebo 2013). These cultural reasons suggesting a positive value to FGM are the main challenge to feminist discourse. At present the feminist discourse arguing that FGM commodifies women in places like Sudan are struggling to get heard. This discourse applied in Sudan and other African countries link FGM to bride-price. Bride-price reduces women to bartered goods traded at marriage, the purer the woman (or girl) the more her family will be given. Campaigns to end FGM are met with a tangled set of abuses. FGM is part of a deeply embedded marriage system projected through cultural values and economic necessity. There are many activists at community level in places like Sudan that articulate similar feminist arguments. However they often find it difficult to be heard above the noise of both the international campaign and the national conservative backlash to the end FGM programme. Of course mind-set change takes many generations but the danger is that rather than coming together, international, national and local end FGM activists, if they are not careful, will speak in siloes and even silence some.

As stated at the start of this section and whilst we place ourselves in this feminist discourse it is important to heed to caution in terms of how we represent women (and men) from cutting communities so as to nurture a dialogue that could lead to change rather than alienate. For example Wade (2009) , Mohanty (2000), Harding (2008), Yuval Davies (1997), James (1998) all argue still that 
writings on the suffering of black women often create (intentionally or otherwise) a binary between 'modernised western women' and 'backward yet to be liberated African women' (see also Nader 1989, Volpp 2000). This is the challenge many face; how to navigate a path to end this practice that is respectful and supportive of the experiences and activism of those affected. In other words, how can we learn and respond to the voices of women affected, rather than impose, assume and further entrench unhelpful racial stereotypes? Wade (2009) in her analysis of the media coverage of FGM talks of the orientalist gaze through which the media reports stories about the brutality of the practice parading victims in a way that verges on voyeurism. For Wade it is not the documenting of the violence that is the issue, nor is it an issue that forthright empowered survivors are given the space to speak, instead it is the way in which these experiences may not be heard as empowered rallying cries but as evidence of the backwardness of the traditions from which the women belong. We argue that there is a danger that the voices of survivors are lost within a more dominant and culturally essentialising response. The End FGM campaign needs to approach the issue from a number of angles including engagement at the grassroots. Locally spaces must be made for survivors and grass root activists to emerge who may approach community conversations using language informed by a closer cultural (but not accepting) reading of the practice and why it persists (see also Eatson, Monkmanik and Miles 2003). This is certainly the view of the women we have interviewed post the Girls Summit 2014 in London and from so-called 'cutting communities', for example:

"When it comes to discussion surrounding FGM its not about women of colour having autonomy over their own bodies but rather creating a space where white women can find self- actualisation through women of colours struggles."

"I have been on this campaign for many years to try and redirect people's attention away from the imagery of FGM that people are being caught up in, especially these past few years due to the international communities pouring millions of pounds on anti-FGM campaigns. The discourse is extremely racist, reductionist and condescending - for most part the discourse is dominated by white feminist but sadly more and more black women are voicing the same dialogue which is very disheartening." (Interview conducted by Bradley May 2014)

It is also evident in the sparse engagement with community groups. For example in an interview with the director of a pan-African community group who attended the Girls Summit 2014 stated:

"The conference did not give any space to the grass roots, it was just a platform for the big and powerful to try and look like they care. Certain figures have risen to prominence in the FGM eradication movement they are claiming to connect with the grass-roots, to understand and to voice the concerns of those affected, however, as a community group and African no-one is interested in what we have to say, no one is engaging with us or supporting our work, it was even pretty impossible to get an invite to this conference, what does that say?” (Interview by Bradley August 2014)

This view was also voiced in an article written by a leading FGM activist and founder of FORWARD: 
'Despite the presence of organisations and individuals from all over the world, there was very little visibility for diaspora and community organisations or individuals. They are the ones who have fought hard to get these issues on the agenda, when large NGOs and the British government were still silent. These are the individuals who've faced rejection from their communities or have described losing their jobs in order to focus on the cause. They have been portrayed mostly as victims and not survivors and agents of change.' (Naana Otoo-Oyortey Wednesday 30 ${ }^{\text {th }}$ July 2014 The Guardian).

In Sudan similar views have been uttered by local activists concerned that ongoing work which precedes the latest wave of programmes is built on rather than side-stepped. In particular a growing urban based youth movement could well provide an already energised and determined platform for change. In other words there is no real need to start from scratch but to identify what already exists and the capital that could be built through more resourcing. Social media additionally and already supports the natural emergence of networks in which issues such as FGM are widely discussed by the young and educated. As one such activist articulates:

I don't understand why international actors think they need to start from the beginning. It may be muted and cautious for obvious reasons, but there are many young people, men and women, who want a different Sudan who endorse conceptions of human rights and see practices such as FGM as abuse. (interview conducted by authors May 2015).

Another local activists based in Khartoum stated: social media such as whatsapp is often vibrant with discussions about FGM. The young are not afraid to voice they views both pro and against. I would say though that there is a clear move towards rejecting FGM whilst a continuing commitment to stay true to Sudanese values and traditions in other ways. (Interview conducted by authors February 2016).

Other conversations reflected on the multitude of FGM campaigns in Sudan and expressed concerned that effort and resources could be sucked into shaping a set of projects that looked coherent from the outside rather than give sufficient energy to empowering and create spaces for local change-agents. Through these comments and viewpoints there is a clear sense that change needs to happen and a will to work towards a Sudan free from FGM/C, with that in mind let us now move to a summary of the various programmes of activity.

\section{Save Sudan from Female Genital Mutilation}

Before we go further we need to outline the FGM picture in Sudan. According to the 1990 Sudan Demographic and Health Survey, 89\% of ever married women in the northern, eastern and western provinces had undergone either Type I or II (15\%) (partial or total removal of the clitoris) or type III (85\%) (which is the most severe form involving infibulation, narrowing of the vaginal opening through the creation of a covering seal). There is as expected internal variation in prevalence and type observed across Sudan. The first Sudan National Household Survey (SNHS) conducted in 2006 among women of reproductive age (15-49) recorded a prevalence average of 69\% in the 15 Northern States 
varying between $40 \%$ in West Darfur and 84\% in River Nile. The 2010 Sudan National Household Survey recorded a national prevalence of any type of FGM at $66 \%$ with internal differences varying between $84 \%$ prevalence in Northern States and $46 \%$ in West Darfur. There are problems with the collection of quantitative data and also with the type of questions asked. This means the picture is far from clear, but what these statistics do tell us is that FGM prevalence is high across Sudan with some states exceptionally so. We can also say that very little change has happened with only tiny reductions in averages rates. In fact these reductions are so slight that they could simply be down to the margin of error expected with statistical analysis.

The difficulties involved in gaining a clear picture of the problem add another dimension to the uphill struggle campaigners are faced with. In the introduction we offered a summary of the prevalence of FGM in Sudan and highlighted how averages map differently across states. However, the survey results looking at FGM in Sudan have been criticised for two reasons; firstly the use of different age cohorts and the other is that most of the existing prevalence rates are based on selfreports of the respondents. Using different age cohorts can influence results. For example the SNHS of 2006 showed a prevalence rate of $69 \%$ based on the circumcision status of all women aged 0-50 years. This was then recalculated using UNICEF's standard indicators for women aged 15-49, which eventually gave a prevalence of $89 \%$ (Ahmed at al 2009). Moreover self-reporting has previously been shown not to be accurate, the statistics may not reflect the real situation on the ground. Evidence existing so far indicates a discrepancy between types practiced and self-reports by women and cutters. In a study in Sudan (Elmusharaf et al 2006) it was found that at least half of the women who stated they had type I (clitoridectomy) and II (excision) FGM/C were actually subjected to type III (infibulations). A second study (Abdel Magied 2002) focusing on midwives asked them to describe the operations they had performed and whilst it was recorded that type I had been carried out, in fact the descriptions fitted type II and III. What these results show is that statistical research alone cannot tell us the whole story and can in fact throw up an inaccurate picture. Given the huge diversity of Sudan it is no surprise that this is the case not least because cultural understanding of the practice varies. The results also highlight that the medical classifications of FGM are not necessarily used by women and girls to describe the practice performed on them. Interventions to end FGM need to respond to these realities; both a lack of clear statistical data and women's own confusion over what level of cutting they have experienced blurs attempts to get a clear picture upon which to build social change.

In Sudan efforts against FGM started in the early 1940s in the form of some state legislation banning the practice (Predie et al 1946). In the 1970's community awareness programmes were introduced run in the first instance by a few NGOs. Community engagement remains a key approach today where we see greater engagement from government and other institutions through to the UN. The National Plan of Action on FGM endorsed by the Ministry of Health in 2001 (led by the National Council for Child Welfare) and also the chapter on FGM included in the Reproductive Health Strategy published by the Federal Ministry of Health, combined are intended to support the work of advocacy groups. The Sudanese Network for Abolition of FGM (SUNAF) is a key actor in the national led movement to end FGM. At federal level attempts through a steering committee have been made to coordinate across advocacy groups and other stakeholders committed to end FGM however it has since folded. At state level there are councils and steering committees motivated to end FGM. At community level we see the work of grass-roots organisation bringing women's groups together with 
religious leaders, midwives, community leaders and youth and children's groups in order to push for behavioural change on this issue. Media campaigns have also been used as a vehicle utilising radio and broadcasting in different languages (UNFPA 2011). Out of the National Action Plan emerged a clear strategy which was endorsed in 2008 feeding into the global push to end FGM within a generation and by 2018. As part of how the global push has translated into the Free Sudan programme the NCCW with other key institutions and councils have drafted a Child Act Bill (2009) to include an article rendering FGM illegal on the grounds of health and social reasons. Unfortunately article 13 of the law which prohibits all forms of FGM/C was removed by the Council of Ministers from the Act following a Fatwa of the Islamic Jurisprudence council which called for a distinction between the various forms of FGM and for Type I, known as Sunna, not to be banned (Medani 2010). Since Sudan follows a federal system states are allowed to have their own legislations and formulate their own child acts. The first states to ratify the Child Act were South Kordofan in 2008 followed by Gardaref state in 2009. The process of ratifying the act in both instances followed a series of activities coordinated by NGOs and other key actors. A workshop opened the dialogue and focused on presenting the statistics, and then presenting the views of Sudanese religious scholars who felt FGM must be abandoned and argued so on religious grounds, or rather by stating that it was not a religious practice. Extensive role out workshops then took place aiming to orientate NGOs, advocacy groups and ministry officials in order to prepare them for the drafting and implementation of the legislation. Reports on the process highlighted the importance of presenting prevalence data as a means of framing the problem that the new act must address. Other states followed in drafting legislation including Blue Nile, Kassala, River Nile and South Darfur.

In addition to the drafting and passing of legislation as a key mechanism in the End FGM programme media campaigns also exist designed to push for mind-set change. The campaigns exist at federal and state levels utilising radio programmes through which key messages are delivered made by religious and community leaders. Role play and songs have also been developed for use in this campaign. TV channels increasingly have covered the issue highlighting the key statistics on prevalence and the consequences of FGM. Media approaches feed into the national Saleema campaign a social movement used to build momentum from the grass roots through to the legislative structures. Saleema is inspired and named after the Arabic word that means whole, healthy in body and mind, unharmed, intact, pristine, in a God-given condition and perfect. Activists involved in creating the movement chose the word Saleema to create a new field of positive association of expectations, for uncut girls and women.

Analysis conducted by the UNFPA on the type and nature of the media campaigning used by the end FGM programme between 2000-2010 identified articles stressing the legal position in relation to FGM and also many that focused on the medical message. In terms of the discourses shaping the interventions we see an integrated approach combining medical and legal activism motivated by a commitment towards gender equality. This carries through into the DFID intervention programme being implemented by UNICEF, WHO and UNFPA. A combination of behavioural change approaches are being used from peer education, use of positive deviants and community conversation. Early evidence suggests that each of these approaches has some impact in terms of changing views on FGM but it is too early to know if they will bring dramatic and sustained change. What we still do not know is what the main and lasting triggers are for long-term mind-set change, until we can generate 
evidence that helps to pinpoint answers to these questions an integrated approach is the best way forward. The approaches used are essentially directed at altering the cultural discourse that still holds firmly that FGM is necessary. The ethics of presenting 'culture as the problem' are fraught not least because it tends to lead to misrepresentation of a country's cultural diversity. Furthermore it assumes there are no change agents inside communities already challenging harmful practices and reinforces global and national hierarchies of power between those that claim to know and those positioned as victims or perpetrators.

Since 2015 when the Free Sudan programme was incepted it has evolved into a complex web or interlocking projects. All the programmes together are referred to as the Sudan Free from FGC. Five key outputs can be identified; social norm change policy, legal reform, evidence on what works, community mobilisation and Capacity Building. The SFFGC is coordinated by NCCW which runs the National Task Force, WHO; who are the end service provider and also responsible for drafting the research strategy (identifying gaps in knowledge in relation to FGM in Sudan), UNFPA acting as the Capacity Building coordinators, UNICEF who are responsible for the social norm change policy.

The UNJP (which DFID also supports) has 3 outputs: legal and policy reform, mobilisation and interventions to end FGM. In relation to output 3 UNICEF coordinates a Sudan based social movement called Saleema which will run for four years targeted states with high prevalence through radio and paper-based advertising (posters, leaflets and T-shirts). In addition to the Saleema movement the Girls Generation are about to launch their movement in Sudan focused on raising visibility of the issue at community level.

To return to the previous section in which the voices of women from within cutting communities were document and made clear their concern that the campaign be guided by those from within. Amongst those views documented were voices from Sudan in particular concerns that the multiple interventions will not converge sufficiently to have any real impact. As one participant told us 'if campaigns are not led by local activists they will not be taken notice of and have little impact' (interview conducted by authors May 2015). Another local NGO worker admitted that some organisations are reorientating their focus to take advantage of the additional funding for FGM (Interview conducted by authors May 2016). This viewpoint echoes arguments made earlier in this article, the discourse policy relations has to be contextualised around the politics of resource allocation that often unwittingly leads to a distortion of discourses for the purposes of organisational survival.

\section{CONCLUSION}

To end this article we return to the various cautionary notes sounded through this article. Discourse around FGM that shape policies and interventions are constantly colliding and being reshaped. This is a reality but the politics of the discourse-policy relationship is such that the drive to dominate coupled with a clambering for resources could severely weaken the potential for joined up activism. There is a real danger that, unless coherence across of stands can me maintained, the programme will become disconnected from the very individuals whose mind-sets need to be shifted but also from those who represent the powerful vehicles for change needed if Sudan is going to be free from FGM. As restated throughout, the inclusion of local voices will be key to programme success. So too though will be the 
acknowledgement that activism to end FGM has not suddenly arrived in Sudan because of this new global programme, put has always existed. These new funds and commitment needs to build on change platforms that precede the programme. However Sudan is at an exciting and crucial movement change, despite the fragile political context, change is happening. Sections of the population (in Sudan and the UK) will no longer tolerate the practice of FGM. Social media and rapid urbanisation with new educational opportunities have opened up networks through which a solid anti FGM voice is gaining strength. These networks are driven and intersect with programmes and institutions that have been working on women's sexual and reproductive health issues for years. The continued inclusion of change agents across the globe will represent the key in terms of the success or not of the end FGM campaign.

\section{References}

Bacci, C. 2000. Policy as Discourse: what does it mean? Where does it get us?, Discourse: the Cultural Study of Politics in Education. 21:1: 45-57.

Bedri, N. 2013. 'Evidence based advocacy for ending FGM/C in Sudan', in The Ahfad Journal Women and Change, 30:1: 9-21.

Bhachu, P. 1993 Immigration and Entrepreneurship: Culture, Capital and Ethnic Networks. New Jersey: Transactions Press, Rutgers University.

Bodian, A. 2015. 'Research Report: Attitudes to Female Genital Mutilation/Cutting in Portsmouth and Southampton’, published by Southern Domestic Abuse Service and African Women’s Forum Portsmouth.

Bourdieu, P. 1977. Outline of a Theory of Practice. Cambridge: Cambridge University Press.

Boyle, E and Preves, S. 2000. National Politics as International Process: The Case of Anti-FemaleGenital-Cutting Laws. Law and Society Review 34:703-737.

Bradley, T. (eds). 2011. Women, violence and tradition: taking FGM and other practices to a secular state Zed Books Ltd.

Burman, E., Smailes, S., and Chantler, K. 2004. 'Culture' as a Barrier to Service Provision and Delivery: Domestic Violence Services for Minoritized Women’, Critical Social Policy. 24 (3): 332357.

Easton, Peter, Karen Monkman, and Rebecca Miles. 2003. Social Policy from the Bottom Up: Abandoning FGC in Sub-Saharan Africa. Development in Practice 13(5):445-458. 
Elise, R, Johansen, B, Nafissatou, J, Laverack, G \& Leye, E. 2013. What Works and What Does Not: A Discussion of Popular Approaches for the Abandonment of Female Genital Mutilation. Obstetrics and Gynaecology Volume 2013.

Elmusharaf, S, Elkhidir, I, Hoffman, S, Almroth, L. 2006. 'A case control study on the association between FGM and sexually transmitted infections in Sudan', in BJOG 113:469-74.

Harding, S. 2008. Sciences from below: Feminisms, postcolonialisms, and modernities. Durham, NC and London: Duke University Press.

Holmes, D.R. 1993. "Illicit Discourse,” in Perilous States: Conversations on Culture, Politics and Nation edited by G.E. Marcus. Chicago: Chicago University Press, 258-81.

James, S 1998. Shades of othering: Reflections on female circumcision/genital mutilation. Signs: Journal of Women in Culture and Society 23:1031-48.

Jean-Klein, I. and Riles, A. 2005. "Introducing Discipline: Anthropology and Human Rights Administrations.” Political and Legal Anthropology Review, 28(2), 175-202.

Jeffery, L. and Candea, M. 2006. "The Politics of Victimhood." History and Anthropology 17(4), 287-96.

Kleinman, A. (ed.). 1997. Social Suffering. Oxford: Oxford University Press.

Longman, C and Bradley, T. eds. (2015 forthcoming), Global Perspectives on FGM/C and other Harmful Cultural Practices and Their Implications for Women's Rights, London: Ashgate.

Malmström, M and Van Raemdonck, A. 2015. '”The Clitoris is in the Head!” Female Circumcision and the Making of a Harmful Cultural Practice in Egypt', in Longman, C and Bradley, T. eds. (2015 forthcoming), Global Perspectives on FGM/C and other Harmful Cultural Practices and Their Implications for Women's Rights, London: Ashgate.

Medani, M. 2010. Criminal law and justice in Sudan. Avaialable at www.pclrs.org/amin_mekki_medani_paper.pdf.

Mohanty, C. 1988. Under Western Eyes: Feminist Scholarship and Colonial Discourses.mFeminist Review 30:61-88.

Nnaemeka, O. 2005. African Women, Colonial Discourses, and Imperialist Inteventions: Female Circumcision as Impetus. In Female Circumcision and the Politics of Knowledge, edited by O. Nnaemeka, 27-46. London: Praeger.

Mohanty, Chandra Talpade. 2003. Feminism without borders. Durham, NC: Duke University Press.

Nader, L. 1989. Orientalism, Occidentalism, and the control of women. Cultural 
Dynamics 2:323-55.

Omar, A, 2015. 'Challenging Mind-Sets on FGM: The Diverse Voices of African Women', in Longman, C and Bradley, T. eds. (2015 forthcoming), Global Perspectives on FGM/C and other Harmful Cultural Practices and Their Implications for Women's Rights, London: Ashgate.

Shell-Duncan, B. 2008. 'From Health to Human Rights Female Genital Cutting and the Politics of Intervention’, American Anthropologist 110 (2): 225-236.

Simpson, J. (2012) Female genital mutilation: the role of health professionals in prevention, assessment, and management', BMJ, 314.

Smith, C. 2011. Who Defines "Mutilation"? Challenging Imperialism in the Discourse of Female Genital Cutting. Feminist Formations 23(1):25-46.

Sudan National Household Survey SMS. 2006. Federal Ministry of Health and UNFPA.

Sudan National Household Survey SMS. 2010. Federal Ministry of Health and UNFPA.

Volpp, L. 2000. Blaming culture for bad behavior. Yale Journal of Law and the Humanities 12:89-117.

Wade, L. 2009. 'Defining Gendered Oppression in US Newspapers: The Strategic Value of Female Genital Mutilation’, Gender and Society 23(3): 293-314.

Werbner, P. 1997. Debating Cultural Hybridity. London: Zed Books.

Yuval-Davis, N. 1997. Gender and Nation. Thousand Oaks, CA: Sage.

\section{Reports and Policy Documents}

AFRUCA 2015 Research Report 'Voices of a Community FGM in Greater Manchester’.

Eliminating FGM An Interagency Statement, 2008 OHCHR, UNAIDS, UNDP, UNECA, UNESCO, UNFPA, UNHCR, UNICEF, UNIFEM, WHO.

FGM/C What Might the Future Hold? UNICEF 2013. 